\title{
Faxinais wordpress: mapeamento das pesquisas sobre faxinais
}

\section{Faxinais wordpress: mapping about research on faxinais}

Edson Struminski

\author{
Universidade Estadual de Ponta Grossa
}

\begin{abstract}
Resumo: Esta nota de pesquisa avalia a produção científica referente à temática dos faxinais, uma forma de uso de solo que envolve comunidades tradicionais do sul do Brasil. Um banco de dados eletrônico (Faxinais worpress) com 60 trabalhos científicos foi criado na internet e os trabalhos foram revistos, com o objetivo de estabelecer parâmetros sobre indicadores da produção científica na área, instituições de pesquisa envolvidas, temas abordados pelos pesquisadores e outros assuntos.
\end{abstract}

Palavras-chave: Faxinais. Produção científica. Banco de dados.

Abstract: This paper is an assessment of scientific literature on the subject of "faxinais", a land use form that involves traditional communities in southern Brazil. For this purpose, an electronic database (Faxinais wordpress) has been created in the Internet, with 60 scientific papers. Each article has been reviewed with the aim of establishing parameters for the scientific production in the area, research institutions involved, and issues addressed by the researchers, among others.

Keywords: Faxinais. Scientificproduction. Database. 


\section{INTRODUÇÃO}

Os faxinais representam uma tradicional forma de uso comunitária da terra, que envolve agricultura, áreas florestais e criação de animais, que vem recebendo atenção crescente por parte de pesquisadores de diversas instituições brasileiras. Já é possível encontrar um número significativo de produções científicas publicadas no formato de artigos para revistas eletrônicas ou teses e dissertações, igualmente em formato eletrônico.

O autor desta Nota de Pesquisa é bolsista do Programa Nacional de Pós-Doutorado e ingressou como professor visitante temporário no curso de Mestrado em Gestão do Território do Curso de Geografia da Universidade Estadual de Ponta Grossa, com o objetivo de estudar aspectos fitogeográficos de um faxinal existente na região de Rio Azul, município do centro-sul paranaense.

Durante a revisão bibliográfica para este trabalho, constatou-se a existência de vários trabalhos publicados em meio eletrônico. Tendo em vista este fato, criou-se um banco de dados em um endereço próprio na internet, que está organizando esta produção e serviu como uma oportunidade para analisar o estado da arte da pesquisa nesta temática, que é aqui apresentada.

\section{PROCEDIMENTOS METODOLÓGICOS PARA A ORGANIZAÇÃO DO BANCO DE DADOS}

A organização da presente pesquisa passou inicialmente pela construção de um banco de dados eletrônico, pela classificação e posterior leitura dos trabalhos disponíveis e, finalmente, por uma avaliação crítica do estado da arte sobre a pesquisa em faxinais.
O banco de dados eletrônico sobre faxinais está disponível para consulta pública. Criado em outubro de 2010, este banco de dados adapta uma plataforma gratuita para blogs disponível na internet (www. faxinais.wordpress.com), o que facilita a comunicação com o público e apresenta 60 trabalhos sobre faxinais já publicados em diversas áreas de conhecimento e em diferentes meios eletrônicos. De modo geral, esta base de dados utiliza a mesma lógica de inserção e indexação de dados das grandes bases existentes na internet, como bancos de teses ou o Domínio Público do MEC, porém facilita o trabalho do pesquisador que trabalha neste "nicho" de pesquisas, pois somente trabalhos sobre faxinais foram selecionados.

$\mathrm{O}$ site apresenta sete categorias provisórias em que os trabalhos foram classificados (cultura, filosofia, legislação, meio biológico, meio físico, meio sócio-econômico e turismo), correspondendo, aproximadamente, às áreas temáticas dos trabalhos, sendo que cada trabalho é classificado somente em uma categoria, para fins de indexação neste site. Entretanto, pode-se constatar que tratam das três grandes áreas de conhecimento: ciências humanas, ciências biológicas e geociências.

A arquitetura do site permite divulgar também palavras-chave (tags) relacionadas aos artigos. Cada trabalho pode receber mais de uma tag. As tags mais citadas recebem maior destaque (as letras da tag aumentam fisicamente de tamanho) no site através de um mecanismo estatístico interno do site. O site possui também outros mecanismos de busca além de um índice de trabalhos inseridos, criado para apresentar todos os trabalhos inseridos. Da plataforma para blogs ele herda a facilidade para a comunicação informal entre os pesquisadores, que podem postar seus comentários sobre os trabalhos. 
Para um trabalho sobre faxinais ser inserido no banco de dados ele necessita inicialmente estar disponível em algum meio eletrônico como um banco de teses, revista eletrônica ou site de depósito de arquivos. Desta forma, ele pode ser rastreado através de buscadores normais da internet (ex: Google acadêmico) ou dos grandes bancos de dados já existentes, como Domínio Público ou Scielo.

Em uma etapa seguinte o trabalho passa a integrar o índice do banco de dados 'faxinais wordpress', geralmente com o nome reduzido apenas por questões estéticas, uma vez que o título integral pode ser muito extenso. Entretanto ele permanece no artigo original. Este índice permite um link com um resumo, sendo que geralmente aproveita-se o existente no próprio trabalho já publicado. Este resumo está disponível em um post do wordpress e permite, por sua vez, acessar um hiperlink com a página da internet onde o trabalho completo pode ser lido ou baixado.

\section{ESTATÍSTICAS DA PRODUÇÃO CIENTÍFICA}

Com base nos 60 trabalhos inseridos no banco de dados sobre faxinais, foi possível fazer algumas inferências sobre as pesquisas realizadas nesta temática.

Estes 60 trabalhos representam o esforço de 72 pesquisadores ligados a 14 instituições, a maior parte delas universidades públicas.

Na tabela 1 vemos que os trabalhos nas áreas de ciências humanas (socio-economia, filosofia, cultura, turismo e legislação) correspondem a 78,34\%, ou seja, 47 dos 60 trabalhos publicados. As ciências da terra (geomorfologia, solos), aparecem com 7 publicações $(11,66 \%)$. Já as ciências biológicas (vegetação, flora, fauna) comparecem com apenas 6 trabalhos (10\%).

Tabela 1 - Distribuição dos trabalhos científicos em faxinais por áreas temáticas

\begin{tabular}{l|c|c}
\hline Área temática & Número de trabalhos publicados & \% do total \\
\hline Socioeconomia & 22 & 36,67 \\
Cultura & 15 & 25,00 \\
Turismo & 4 & 6,67 \\
Filosofia & 2 & 3,33 \\
Legislação & 4 & 6,67 \\
Meio físico & 7 & 11,66 \\
Meio biológico & 6 & 10,00 \\
TOTAL & 60 & 100 \\
\hline
\end{tabular}

Fonte: www.faxinais.wordpress.com Org: autor

Já conforme podemos ver na tabela 2, as duas instituições que mais publicam trabalhos sobre faxinais são a Unicentro, Universidade Estadual do Centro Oeste, com campus nas cidades de Guarapuava e Irati e a UEPG, Universidade Estadual de Ponta Grossa. Ambas são instituições de ensino superior do Estado do Paraná, mantidas pelo governo estadual na porção central interior deste estado, a área geográfica onde mais se encontram faxinais remanescentes no Brasil. Juntas estas duas instituições congregam $59,71 \%$ dos pesquisadores envolvidos em pesquisas sobre faxinais e $64,15 \%$ dos pesquisadores citados como autores em pesquisas publicadas. Conforme comentou-se, 72 pesquisadores estão envolvidos nos 60 trabalhos listados. De modo geral, são mais comuns os 
trabalhos produzidos individualmente $(49,15 \%)$, mas muitos pesquisadores costumam produzir trabalhos em equipes, sendo que alguns deles aparecem com mais frequencia, tendo mais de um trabalho publicado na temática dos faxinais, geralmente na forma de dupla $(35,59 \%)$, a outra forma mais comum de produção de trabalhos. Com isto, no total, o número de vezes que o nome dos pesquisadores aparece como autores em trabalhos publicados (citações como au- tores) é de 106, o que sugere a existência de um intercâmbio considerável entre os pesquisadores. O mais comum é um autor publicar um ou no máximo 2 artigos sobre este tema, com uma notável exceção. Há um importante destaque individual neste ranking de pesquisas para Löwen Sahr (socioeconomia, cultura, geografia) da UEPG, que individualmente ou como co-autora, assina $10,37 \%$ deste total de 106 participações, mais do que muitas das demais instituições somadas.

Tabela 2 - Distribuição da produção científica em faxinais por instituições e pesquisadores

\begin{tabular}{|c|c|c|c|c|c|}
\hline Instituição & $\begin{array}{c}\text { Número de } \\
\text { pesquisadores } \\
\text { envolvidos em pesquisas }\end{array}$ & $\%$ & Instituição & $\begin{array}{l}\text { Pesquisadores como } \\
\text { autores em pesquisas } \\
\text { publicadas }\end{array}$ & $\%$ \\
\hline Ufpa & 1 & 1,38 & Ufpa & 1 & 0,94 \\
\hline UNESP & 1 & 1,38 & UNESP & 1 & 0,94 \\
\hline UFRGS & 1 & 1,38 & Iapar & 1 & 0,94 \\
\hline UFRN & 1 & 1,38 & Fajar & 1 & 0,94 \\
\hline UFSCar & 1 & 1,38 & Ing & 1 & 0,94 \\
\hline USP & 1 & 1,38 & USP & 2 & 1,88 \\
\hline Embrapa & 2 & 2,79 & Embrapa & 2 & 1,88 \\
\hline Iapar & 1 & 1,38 & UFRGS & 2 & 1,88 \\
\hline Ing & 2 & 2,79 & UFSCar & 3 & 2,83 \\
\hline Fajar & 1 & 1,38 & UFRN & 3 & 2,83 \\
\hline UFSC & 3 & 4,18 & UFSC & 4 & 3,78 \\
\hline UFPR & 10 & 13,90 & UFPR & 13 & 12,27 \\
\hline Uepg & 15 & 20,84 & Uepg & 33 & 31,14 \\
\hline Unicentro & 28 & 38,89 & Unicentro & 35 & 33,03 \\
\hline S/I & 4 & 5,57 & S/I & 4 & 3,77 \\
\hline TOTAL & 72 & 100,00 & TOTAL & 106 & 100,00 \\
\hline
\end{tabular}

Fonte: www.faxinais.wordpress.com Org: autor 


\section{ANÁLISE TEMPORALDA PRODUÇÃO CIENTÍFICA}

Muito embora haja uma constatação unânime de que os faxinais são sistemas de uso do solo com 100, 200 ou mais anos, ou seja, que possuem uma origem antiga no Brasil, podendo ser considerado um uso do solo tradicional, a pesquisa sobre este tema é bastante recente. Os chamados "clássicos" sobre faxinais datam de fins do século XX. O primeiro e, sempre citado, texto de Chang (1988), trabalho este que já falava sobre a desagregação de faxinais e a outra autora tida como clássica é Nerone (2000).

Com isto temos que praticamente toda a produção científica sobre faxinais data do século XXI. 97\% dos trabalhos disponibilizados no portal faxinais foram produzidos a partir de 2001. Curiosamente, a legislação que versa sobre faxinais é de 1997, antes, portanto, que uma maior noção sobre a diversidade de assuntos sobre faxinais pudesse ter sido produzi$\mathrm{da}$, inclusive sobre aspectos ambientais de faxinais, que aparece como uma área deficitária em pesquisa.

\section{CONCLUSÕES}

Os números aqui apresentados são parciais, mas já demonstram que as universidades regionais encontraram uma temática também regional significativa e que faz jus à vocação de entendimento do seu próprio mundo, que estas universidades devem possuir. As pesquisas têm se concentrado em aspectos humanos dos faxinais, como a cultura, o turismo, aspectos étnicos, ou mesmo sócio-econômicos das comunidades faxinalenses. Os trabalhos são muito recentes, praticamente todos contemporâneos e muito similares, influenciando-se e citando-se mutuamente, não havendo uma temporalidade distinta, o que, de certa forma, impede uma maior avaliação crítica desta produção.

Mesmo assim percebe-se que as pesquisas pouco têm investido em aspectos relevantes para a conservação e manejo dos faxinais, como mapeamentos de solos, biológicos ou florestais, que poderiam trazer melhorias diretas para a produção agrícola, florestal ou pecuária dos faxinais, o que sugere a necessidade de maiores investimentos em pesquisas que trariam mais retornos aos faxinais. Paradoxalmente, os pesquisadores, que valorizam muito este sistema, têm assistido e constatado o desaparecimento de áreas de faxinais, pouco contribuindo para sua manutenção, mesmo sendo áreas ecológica e culturalmente propícias para a implantação de experimentos agronômicos, de melhoria do plantel genético de animais ou silviculturais.

De qualquer modo, do ponto de vista do auxílio à pesquisa, a organização de um site que reúne pesquisas sobre faxinais representa um facilitador aos pesquisadores. As visitas a este site eram de 3,4 por dia entre outubro de 2010 a março de 2011. Passaram a 12,4 por dia no mês de abril de 2011, atingindo 18,2 visitas por dia no mês de maio de 2011 e mais de 30 ao dia em junho de 2011. Provavelmente deverá atingir um número regular de visitas à medida que seu endereço na internet seja divulgado e possa ser mantido atualizado, algo que ocorreu a partir do I Simpósio de Pesquisadores de Faxinais, que ocorreu em julho de 2011 na UEPG.

Sem pretensões de concorrer com as grandes bases de dados, o site 'faxinais wordpress' poderá ir se ampliando ao longo do tempo, tornando-se uma referência na pesquisa em faxinais. 
O estudo aqui apresentado, mesmo sendo uma amostragem deste universo científico, já permite uma maior visualização do estado da arte sobre a pesquisa neste tema. Principalmente permite que os pesquisadores constatem, por si só, as demandas não atendidas sobre este tema.

\section{REFERÊNCIAS}

CHANG, M. Y. Sistema Faxinal: uma forma de organização camponesa em desagregação no centro-sul do Paraná. Londrina: IAPAR, 1988.

NERONE, M. M. Terras de plantar, terras de criar Sistema Faxinal: Rebouças - 1950-1997. Assis, Tese (Doutorado em História) - Universidade Estadual Paulista. 2000.

www.faxinais.wordpress.com

Recebido em: 28/09/11 Aceito em: 05/11/11 